Portland State University

PDXScholar

Fall 3-11-2016

\title{
Is Scholarship Advancing?: An Analysis of Fifteen Years of Framing Research
}

Joseph Zachary Provencher

Portland State University

Follow this and additional works at: https://pdxscholar.library.pdx.edu/open_access_etds

Part of the Speech and Rhetorical Studies Commons

Let us know how access to this document benefits you.

\section{Recommended Citation}

Provencher, Joseph Zachary, "Is Scholarship Advancing?: An Analysis of Fifteen Years of Framing Research" (2016). Dissertations and Theses. Paper 2705.

https://doi.org/10.15760/etd.2701

This Thesis is brought to you for free and open access. It has been accepted for inclusion in Dissertations and Theses by an authorized administrator of PDXScholar. Please contact us if we can make this document more accessible: pdxscholar@pdx.edu. 
Is Scholarship Advancing?: An Analysis of Fifteen Years of Framing Research

by

Joseph Zachary Provencher

A thesis submitted in partial fulfillment of the requirements for the degree off

Master of Science

in

Communication

Thesis Committee:

Cynthia-Lou Coleman, Chair

Jeffrey Robinson

Cornel Pewewardy

Portland State University

2016 


\begin{abstract}
In 2011, Porismita Borah published "Conceptual Issues in Framing Theory: A Systematic Examination of a Decade's Literature" to shed light on the status of framing research, and attempt to answer several scholars' criticisms of framing research practices (Carragee and Roefs 2004, D'Angelo, 2002, Entman, 1993). Borah argues that framing research has several areas of necessary improvement, and her prescription is for future research to be able to examine specific framing issues or effects, but also be able to connect with broader understandings of framing.

The following content analysis of framing research, conducted between the year 2000 and 2013, seeks to examine the current state of framing literature, and whether or not scholarship is advancing optimally. The hope is to examine partially if Borah's concerns remain relevant to current framing research. Additionally, the current study seeks to expand the questions asked of framing research in multiple ways. What follows is an account of framing, as a theory broadly. Borah's role in attempting to measure the state of framing research is explained, and then I show how research can be expanded in several areas to be more inclusive. Then, new avenues of inquiry will be opened, particularly in regard to power, and social relationships, to delve deeper into whether or not framing research can be improved in terms of accuracy and efficacy.

Following those sections is an explanation of the way my research questions have been operationalized, an account of the methodology employed by this study, our findings, and a discussion of the data and its meaningful portions.
\end{abstract}




\section{Dedication}

Dedicated to my mother, father, and little brother Miles. It's hard to live so far away, and see you all so infrequently. Your support has meant everything. I hope I make you proud. 


\section{Acknowledgments}

First and foremost I would like to thank my thesis chair, Dr. Coleman for everything she has done. Her mentorship has proven to be invaluable, and her leadership instrumental in orchestrating this research. Her particularly accessible and empathetic pedagogy was essential to every part of this project, and to my growth as a student. Dr. Coleman has challenged me, while never making me feel academically abandoned, or inadequate. The first time meeting Dr. Coleman, she shook my hand and personally accepted a copy of my application to the graduate program at Portland State. She instructed my first graduate only class, in Communication theory. Ever since, I have done my best to make her proud of my work and accomplishments. Thank you sincerely.

I would also like to thank the rest of my thesis committee, Dr. Robinson and Dr. Pewewardy. Both professors generously volunteered their time and energy to improve my work, and offer me guidance through this process. Their generosity and patience is greatly appreciated. Additionally, their feedback and comments helped greatly in shaping my work, and assisting me to always remember to see the forest for the trees.

It is also imperative to thank the excellent undergraduate students who served as coders and helped me conduct the research. As coders, Nate Chart, Janette Hess, and Ron Kyuath all were valuable and essential team members who worked tirelessly, and supported me through the whole process. Even when my leadership 
faltered, all three researchers stepped up and performed admirably. Working with such a dedicated crew inspired me, and elevated my efforts on the project.

I also would like to acknowledge Ben Smith, who helped initially design the project, as well as assist me with methodologically. Ben's attention to detail, and patience explaining potential goals and obstacles of the project early on were critical in ensuring the success of the research.

Additionally, I want to acknowledge all the students involved in the project. Organizing all the journals, and getting articles together would not have been possible without Timira Cobbs, Erin Niemela, Charles Randolph, Jenny Woodman, Therese Lang, Alesha Sangster, Amanda Pile, and Emily Lightcap. This project all started with twelve students from a framing class coming together to ask further questions. Given that the framing class was taught over a ten-week term, it served only as an introduction to the discipline. As such, the above-mentioned students were eager to explore more.

Designing and executing the study was new territory for me, and for those involved. In addition to the patience displayed by the entire team, their help in planning, designing, and helping co-create this research was invaluable.

More broadly I want to acknowledge the entire cohort of graduate students I studied along side at Portland State University: Hillary U'ren, Adam Testerman, Rebecca Smith, and Alex Brehm. Your support and friendship through the entire degree process was crucial to me reaching the point of writing and completing a thesis. I have heard stories of cohorts who fight, and compete against each other for 
department attention, or resources, or what have you. I always appreciated the sincerity in which we supported each other, and raised each other up at every opportunity. I cannot imagine surviving the graduate program without your collective support.

Lastly, I would like to thank Dr. Shaker, who while not involved heavily in the project specifics has been my friend and mentor for the past two years. Thank you for keeping your office door open to me at all times. Being able to drop in and ask your advice on everything from thesis project details, to taking the next step to pursue my PhD meant so much to me during my time at Portland State. Your guidance was reassuring, and helped give me the confidence and skill set to fulfill my goals. I am sincerely grateful. 


\section{Table of Contents}

Abstract $\quad$ i

Dedication $\quad$ ii

Acknowledgements

List of Tables vii

List of Figures viii

$\begin{array}{lr}\text { Framing } & 1\end{array}$

How We Ought to Study Framing $\quad 5$

$\begin{array}{ll}\text { Scheufele’s Model } & 14\end{array}$

$\begin{array}{ll}\text { Borah's Contributions } & 16\end{array}$

Beyond Borah: Accounting for Power Relationships 19

$\begin{array}{ll}\text { Operationalizations } & 23\end{array}$

$\begin{array}{ll}\text { Methodology } & 38\end{array}$

$\begin{array}{ll}\text { Results } & 44\end{array}$

$\begin{array}{ll}\text { Discussion } & 49\end{array}$

$\begin{array}{ll}\text { Limitations } & 60\end{array}$

$\begin{array}{ll}\text { References } & 63\end{array}$ 


\section{List of Tables}

Table 1 - Mixed Frames 


\section{List of Figures}

Figure 1 - Framing Effects

Figure 2 - Basis of Frame Codes

Figure 3 - Framing Effects Approach

Figure 4 - Method Coding

30

Figure 5 - Mixed Frames Approach

30

Figure 6 - Process Coding

32

Figure 7 - Frame Arena Coding

Figure 8 - Frame Variable Coding

Figure 9 - Frame level Coding 


\section{Framing}

Walter Lippmann's (1922) seminal work Public Opinion lays the foundation on which modern framing theory is built. Lippmann's four main points of analysis seek to understand the role public opinion plays in democracy, the significance that stereotypes have in forming public opinion, the ability of news media to identify and select news, and lastly and most importantly, Lippmann forwards an argument that individuals' interpretations and perceptions of reality are filtered or augmented through the media. His chapter, The World Outside and the Pictures in Our Heads, makes the case that people have little direct experience with most of what happens in the world. Intuitively, Lippmann argues that without the ability of an individual to experience world events first hand, media representations become the only avenue to garner knowledge of the world.

Lippmann also argues that public opinion is often the result of existing stereotypes. Individuals develop stereotypes as they interpret information, both as a defense mechanism as well as for the sake of an economy of effort. Lippmann asserts that given the plethora of information confronting an individual, heuristic stereotypes become a way to quickly filter and process information. It should be noted that Lippmann does not provide a very robust definition or explanation of stereotyping in his work. However, such work is not necessary for his broader argument. Lippmann's argument does not require a full explanation of the psychological causes and effects of stereotyping, rather, he only seeks to show that 
individuals will generally process information by interpreting stimulus through the pathways of least resistance and effort.

Because stereotyping offers a quick and easy way to process a large volume of information, we can expect individuals to use these heuristics. Combining these arguments with his analysis of the role media play in shaping public perception lays the foundation to understand the way information flows from the media to the public. Specifically, his writings demonstrate that the selective power of media has an impact on public opinion. Agenda setting, gatekeeping, and most importantly, framing research have great interest in such reactions. This suggests the necessity to understand the intentional constructions of information as presented by the media. Because the media have a vested interest in maintaining the attention of the public, while also being partially responsible for the attitudes possessed by the public, scrutiny as to the context that media present information is warranted.

It is also important to note Lippmann's skepticism in regards to journalists. Journalists possess only as much ability to accurately portray information as any other individual could in their circumstances. This is to say that reporters are human, and subject to the same biases in perception of much of the public. Human cognition necessitates an inescapable amount of subjectivity (Lippmann, 1922).

Following Lippmann, Goffman (1974) offers a broad conception of framing as a theory. Goffman argues that framing aids individuals in processing and organizing everything they see during their daily experiences. Referring to frames as schemata of interpretation, Goffman posits a succession of events one experiences would be meaningless absent a framework to aid in making coherent the interpretation of 
said events. Absent these schemas, or "primary frameworks" (Goffman, p. 24), individuals would constantly struggle to interpret their life experiences, and be unable to classify information and interpret it meaningfully.

Continuing to focus on media, Gitlin (1980) argues that frames are devices that allow journalists to organize vast amounts of information and package them effectively for their audiences. He explains frames as "persistent patterns of cognition, interpretation, and presentation, of selection, emphasis, and exclusion" (Gitlin, p. 7) that serve to properly organize information both for journalists and their audiences.

Other scholars argue that framing not only occurs in media texts, but also, can occur anytime an individual makes a decision. This psychological approach to framing seeks to demonstrate that any time an individual processes information, the framing of said information plays a crucial role in an individual's interpretation of meaning. Tversky and Kahneman's (1981) work, “The Framing of Decisions and the Psychology of Choice" investigates several instances of framing that correlate to individual decision-making. Their scholarship uses the major theory of decisionmaking under the context of potential risk risk as the expected model for individual behavior, arguing that when faced with a choice, a rational decision-maker will prefer the prospect that offers the highest expected utility, given that the expected utility of a prospect is equal to the expected utility of its outcomes (obtained by assessing the utility of each outcome relative to the probability of said outcome). This foundation allows Tversky and Kahneman to analyze the framing of acts, the framing of contingency, and the framing of outcomes. Variations of the reference 
point individuals possess (the way the prospect is framed) determine whether a given outcome is evaluated as a gain or a loss, implicating the perceived level of risk, and risk-aversion, of the potential action. Tversky and Kahneman find that "seemingly inconsequential changes in formulation of choice problems caused significant shifts of preference", which suggests the changes in formulation of choice should be understood as manipulating the ways in which the hypothetical choice problems are framed. Tversky and Kahneman identify these manipulations as variations in the framing of acts, contingencies and outcomes. Additionally, "the demonstrated effects are large and systematic", proving the existence of powerful framing effects (although it should be noted that Tversky and Kahneman clarify these effects are by no means universal) (Tversky \& Kahneman, 1981, p. 457). Scheufele and Tewksbury (2007) summarize that "framing therefore is both macro level and micro level construct" (p. 12). As a microlevel construct, framing describes how individuals form impressions or judgments about a potential choice, based on the presentation features of that choice. However, the term "framing' also refers to the ways in which journalists and other communicators present information in order for that information to resonate with existing understandings and common schemas among their audience. This should not be mistaken as an argument that journalists use framing to intentionally deceive their audiences, but rather, that framing is a necessary tool to reduce the complexity and unfamiliarity of content to their audience in service of their communication goals. Scheufele and Tewksbury identify this behavior as a macro level construct. 


\section{How We Ought to Study Framing}

Robert Entman offers further clarification of framing. Unlike Goffman, Entman focuses on salience as a way to understand a given frame.

"To frame is to select some aspects of a perceived reality and make them more salient in a communicating text, in such a way as to promote a particular problem definition, causal interpretation, moral evaluation, and/or treatment recommendation for the item described" (Entman, 1993, p. 52).

In his article, Framing: Toward Clarification of a Fractured Paradigm, Entman lays the case for establishing a consistent concept of framing, while understanding framing and framing effects in a pluralistic fashion. While he does not deny the intersectional nature of framing, and acknowledges its ability to manifest itself across a broad spectrum of communication, as well as other social scientific research, Entman (1993) insists on doing more to bring framing into a single, consistent, and explicit paradigm.

One of the many benefits of Communication, as a discipline, lies in its ability to bring together many disciplines, and embrace the interchange of scholarship. While some argue that Communication lacks a deficient core of knowledge, Entman (1993) argues a flexible core allows for greater strength than weakness. Static interpretations of research paradigms as requiring a comprehensive statement to guide research risks discarding and scattering hypotheses and research across a wide range of fields without bridging research for maximum benefit. "By bringing ideas together in one location, communication can aspire to become a master 
discipline that synthesizes related theories and concepts and exposes them to the most rigorous, comprehensive statement and exploration" (Entman, p. 51).

Entman argues for such measures in order to ensure research accuracy, as well as relevancy. It is important to understand exactly the way research functions, either within, or outside, an existing paradigm, and the ways in which paradigms affects research quality. Thomas Kuhn's seminal work, The Structure of Scientific Revolutions (1970) documented the shift the scientific community has taken over a variety of issues over the years. Kuhn frames these shifts in terms of dominant paradigms, anomalies, and eventually, revolution. In the book, Kuhn (1970) documents several instances where the scientific community at large worked under what he defined as a dominant paradigm. The paradigm established all of the norms for how scientists designed experiments, tested hypotheses, and published results. However, frequently, the dominant paradigm would be incorrect about explaining the function of a particular phenomenon. This happened frequently in the study of electricity. Eventually, some experiments did not return the expected results. These at first were dismissed as anomalies, assumed that a flaw in experiment design, or execution caused the result. However, with repetition of similar experiments, eventually the anomalies begin to pile up, and the scientific community can no longer ignore the building of research that suggests their understanding of, say electricity, contains deep flaws. This is when Kuhn suggests that revolutionary science occurs. Kuhn documents failings in electricity, nuclear physics, and many other instances where the dominant paradigm was wrong. Entman's (1993) concern 
is that absent a coherent paradigm, framing research lacks the ability to advance itself the way other scientific research has.

Framing lacks a general statement of framing theory that shows precisely how frames come to be: how they are embedded or manifest within text, or framing's influence on the thinking of individuals or groups. Despite its omnipresence across social sciences and humanities, framing lacks clarity, which harms the ability of framing research to be truly productive. Absent a consistent paradigm, it becomes very difficult for framing research to build on itself. Entman (1993) fears that scholars will produce, and reproduce, work that does not exist within a stable and consistent context, and as such, does not help contextualize other scholarship. If Communication scholars produce and reproduce similar, if not equivalent types of, research without being aware of the similar scholarship of others, then researchers fail to build upon one another, and continue to advance the field as a whole. To borrow from Kuhn (1970), without a soundly defined paradigm, it is impossible to know if research is contributing to solidifying the explanatory power of a theory, or if it is playing a role in deconstructing an inaccurate dominant paradigm.

In addition to its lack of central statement, Entman also identifies the casual overlapping of terms used to study framing, words such as "frame", "framing", and "framework" which are not always used by authors to identify framing as a communication theory, or to contribute to the cannon of framing research. Entman suggests that framing is often inadequately defined with much left to an assumed mutual understanding with the reader and researcher. 
Entman furthers the need for a more consistent approach to framing research, given the implications of potential framing effects. In texts, frames highlight certain bits of information about an item by elevating them in salience (salience defined by Entman as "making a piece of information more noticeable, meaningful, or memorable to audiences" p. 52). To understand framing is to understand the way a communicated text exerts power or influence. This understanding precludes the ability to accurately research audience autonomy, journalistic objectivity, accuracy of content analysis, public opinion and normative democratic theory, and any other effect of discourse on society, or the individuals within. In short, framing implicates the meanings communicated by a text, or discourse. As such, investigating, and perhaps deconstructing, the framing that occurs in text and discourse is a necessary step to understand the power, influence, and effects of that communication. It is a prior question, and potentially an a priori concern, necessitating investigation before being able to fully unwrap all aspects of communication. Answers to the existence of framing, and the implications as such, need establishment before the accuracy of other research, and the veracity of those truth claims as it pertains to acts of communication, can be accurately assessed.

This desire to create a common dominant paradigm, in the Kuhnian sense, is not shared by all, as scholars remain divided on how best to approach framing studies. Paul D'Angelo, in his work News Framings as a Mutliparadimatic Research Program: A response to Entman (2002) makes the case against pursuing a single paradigm of framing research. Rather, researchers in the communication discipline should be encouraged to use specific theories to progressively explicate a complex 
process (that of framing). Knowledge about framing, D'Angelo argues, has accumulated in virtue of researchers employing and refining many theories about the framing process. This work benefits from theoretical and paradigmatic diversity, avoiding the risk that research findings end up fragmented in isolated research agendas.

D'Angelo worries that Entman's prescription for framing research inhibits and constrains knowledge gains. D'Angelo accuses Entman of supporting the establishment of a Kuhnian paradigm, which limits the possibility of research. Entman's call for a single "coherent theory" of framing fails to take into account that various (perhaps seemingly exclusive, or competing) theories may be required to understand framing. D'Angelo argues that researchers should utilize any and all available theories in order to examine particular aspects of the framing process, "for theories are supposed to generate inconsistencies, which, in turn, provide new directions for future research" (D’Angelo, p. 873). However, even though he argues against limiting framing research to a single paradigm, D’Angelo clearly advocates for "congruity between theory and paradigm" in order to allow for revisions of theoretical models. D'Angelo agrees with Entman that framing exists as a "scattered conceptualization", as findings from framing research have not yet accumulated into a cohesive body of knowledge. D'Angelo argues that the mission of the communication discipline is well served by these accomplishments so far, since there has been such a broad range of approaches to framing research.

This is epically relevant given the broad range of frames, and framing effects. D’Angelo argues that frames "lead a double life as 'internal structures of the mind' 
and 'devices embedded in political discourse" (D'Angelo, p. 873). The "internal structures of the mind" refers to the cognitive states of individuals, where frames exist as prior knowledge. This functions to aid the individual in efficiently processing information conveyed to them, and intersects nicely with Lippmann's previous arguments as to the effects of news frames influencing the attitudes and beliefs of individuals. They key distinction here is acknowledging that there can be frames in a communicative text, as well as in the mind of the receiver of said text. These mental frames also are present when individuals converse about political issues (D'Angelo, 2002). Additionally, frames operate within routines and discourses of groups and organizations. D'Angelo argues that framing shapes public dialogues about political issues. He identifies journalists as playing a "conduit" role to transfer information to citizens that enable them to understand politics, and garner agency to act politically. As a result, framing research concerns itself with how well journalists accomplish this task, resulting in scrutinizing the issues selected as salient within media texts.

Tension between D'Angelo's and Entman's approaches call for further research necessitates further research. Entman is concerned that there is no dominant paradigm to framing research, while D'Angelo thinks pursuit of a common paradigm might harm the potential of framing scholarship. I therefore propose the following research questions:

$\mathrm{RQ1}(\mathrm{a}):$ Is there a dominant paradigm of framing research? RQ1(b): In framing research, what is most common: the study of unique frames, or the study of theory-based frames? 
The first research questions seek to uncover if a dominant paradigm in framing exists, in order to address the fundamental tension between D'Angelo (2002) and Entman (1993). In order to do so, it is important to see how often researchers use each other's work in order to further the study of framing. To test this, coders were asked to identify if the frames under study in any given article were "Unique" or "theory based.

For the purposes of the current study, a "theory" frame originates explicitly from prior literature. A "unique" frame originates from the material being studied, or in some other way is non-attributable to prior research. . For example, Coleman's 2013 analysis of news coverage of an ancient skeleton discovered in North America revealed unique frames of simulacra and synecdoche that framed the skeleton as Jean-Luc Picard, a fictionalized and futuristic Starfleet commander. Additionally, frames about war and battle contests (highlighting conflicts between tribe members and scientists), science versus religion (with science elevated to a superior status), the rights and legitimacy of key stakeholders (tribe members, scientists, the courts, and the federal government) as legal and moral, and "progress" as a description of stakeholder platforms all emerged from study of media text, without previous authorship describing and documenting the existence of said frames.

Theory frames, however, allow the researcher to invoke framing literature when designating and measuring frames. For example, Coleman, Hartley and Kennamer (2006) assert that common frames seen in prescription drug news coverage include costs, benefits and drawbacks, frames previously investigated which they, in turn, adopted for their 2006 framing study. 
Determining the answers to these questions also helps to respond to the tension between Entman (1993) and D'Angelo (2002). One of D'Angelo's (2002) central claims is that Entman's (1993) concern is ill founded, since allowing research to develop organically will produce optimal results. It is important to know, then, how often scholars are using previously established and studied frames to base their investigations (i.e. theory-based frames), as opposed to pursuing research that uncovers the existence of a frame or a framing effect without prior assumptions (i.e. unique frames). This is essential to know if scholars are building on each other's work, and as such, if a dominant paradigm exists within framing studies.

Current researchers attempt to shed light on framing, while incorporating both aspects of individual as well as textual framing. In his work, "Framing as a Theory of Media Effects" Dietram Scheufele (1999) seeks to differentiate framing from other related concepts in mass media effects research. In a return to Entman's fractured paradigm, Scheufele argues for a general conceptual definition of framing, involving identifying theoretical premises common to all conceptualizations of framing, in order to develop a definition of framing applicable specifically to media effects research. Within the realm of political communication, Scheufele argues that framing must be defined and operationalized on the basis of acknowledging that mass media actively set the frames of references that readers and viewers use to interpret and discuss public and/or political events. However, preexisting meaning structures, or schemas, mitigate the effects of mass media framing. 
This necessitates analysis of the roles that audiences and mass media play in this constructivist approach. Scholars argue that framing occurs on two distinct levels (Tewksbury, Jones, Peske, Raymond, and Vig, 2000, Scheufele, 1999). On one level, there are the individuals who operate actively in the construction of meaning, both through individual-level cognitive processing, as well as through social interactions and communication. On a second level, there are the mass communication framing elements constructed by media, which may have effects on a great number of individuals given the media saturated environment many live in. Scheufele identifies a lack of research examining the interplay between these two levels, and argues for the establishment of an interactive model of the construction of reality.

Scheufele considers frames to be schemes both for presenting and comprehending news, necessitating understanding framing on an individual level and media level. Often this results in studying frames as both independent and dependent variables. Studies that treat frames as an independent variable typically investigate the effects of framing. In the case of message framing, frames are usually introduced to examine the effects on the audience of said message. In the case of individual, or cognitive frames, Scheufele is interested in examining the role individual framing of issues influences evaluations of issues and/or political actors.

Here Scheufele lays the foundation for operationalizing framing. As a prescription for future research, Scheufele identifies four key processes by which frames come into existence: frame building, frame setting, individual level processes of framing, and a feedback loop from audiences to journalists. 


\section{Scheufele's Model}

Frame building is research that investigates how frames are formed, including the processes that influence the creation or alteration of frames. Generally, these sorts of studies engage in content and discourse analysis to understand where the frame arises. Frame setting describes research that examines the ways frames enter public or societal consciousness. Typically this research investigates public perception of either a frame, or of a particular event, in order to determine the existence of a frame in society at large. Individual level processes of framing describe research invested in the way individuals are affected by frames. This research typically examines individuals' attitudes, beliefs, or knowledge in order to assess framing effects, or the existence of frames in particular individuals.

Lastly, Scheufele describes feedback effects. This research attempts to dig deeper into the role that journalists, and others, play in constructing media level frames. Because journalists are also members of the public, and exist in the same social location as other individuals, frames that exist at a public or societal level may affect the individual attitudes or beliefs of a given journalist or media actor. In turn, Scheufele expects those frames to influence the way that said media actors construct their media products, resulting in impacting the media products that construct media frames (Scheufele).

The four stage model has great explanatory power. Framing effects can be traced from the creation of the frame, to the impact on the public, individuals within the public, and then again to individuals responsible for the creation or alteration of 
frames. While adequately laying out a foundation to start further research in these various ways, Scheufele merely prescribes these approaches. In many ways, this is not a complete answer to Entman's (1993) criticism. Just because Scheufele is able to offer a model under which most framing research will fit, does not mean that scholars are engaged in actively categorizing their work as such. The existence of Scheufele's model then, does not inherently address whether or not framing research is being conducted under a common dominant paradigm. However, this model is likely only as valuable as it accurately represents the field of framing research. If it can be demonstrated that framing research is being conducted at each of the levels Scheufele describes, then scholarship may come closer to a consistent approach to framing research, as described by Entman. Further research ought take up the charge, and investigate these dimensions to framing research.

I therefore pose the following research questions, based on Scheufele's model of framing effects research:

RQ2(a): To what extent does framing research attend to frame building? RQ2(b): To what extent does framing research attend to frame setting? RQ2(c): To what extent does framing research attend to individual level effects?

RQ2(d): To what extent does framing research attend to feedback effects? 


\section{Borah's Contributions}

One avenue to address Scheufele's (1999) critique of framing research is to capture the ways in which research has unfolded. Porismita Borah (2011) takes an initial step at answering some questions about framing research. Her study, "Conceptual Issues in Framing Theory" surveys framing research from the years 1997-2007 in order to begin to draw conclusions as to the current state of framing research. Borah selected every journal identified as a "communication journal" in the Journal Citation Report, from the Institute for Scientific Information's Social Sciences Citation Index, was included. A total of 44 journals were studied. Additionally, keyword searches (using the terms "framing", "frames", "media framing", and "framing effects") in electronic databases were used to capture additional journals from the following: the ISI social sciences Citation Index, PsychINFO, Communication Abstracts, Sociological Abstracts, and ProQuest Research Library. The keyword searches resulted in an additional 68 journals.

Borah searched through the journals, using the terms "framing," "frames," "media framing," and "framing effects." All articles including these words or phrases were included in the sample. This seems a sound research design to launch a content analysis of articles published about framing research. As will be addressed later, Borah employed this design but asks a limited number of research questions.

Borah is interested in partially answering Entman's (1993) criticism of framing's fractured paradigm. To do so, she recommends reviewing the literature to determine if any given framing study is actively investigating frames already 
considered to exist, and have effects (as per prior research) or if researchers are uncovering and discovering new frames, previously undocumented in scholarship. This question seems essential to be updated in order to determine answers to Entman's (1993) concern.

Additionally, Borah investigates two other methodological concerns for framing research. First, that framing research has the ability to test effects in a way that does not suffer too greatly from threats to external reliability. Often times, framing effects are done so as to isolate a single frame, and its impact on any given subject(s). However, frames are present in a variety of situations and contexts, and as such, in the real world outside the laboratory, it is unlikely for an individual to experience framing effects in such a vacuum. Other authors have argued that many decisions individuals make are a choice between competing values, or competing frames (Sniderman \& Theriault, 2004). Given the use of frames to package information to an audience, it is likely that the audience is asked to interpret information that either contains more than one frame, or interpret information framed one way while also interpreting different information framed another. It will be important to see if current framing research is cognizant of this, and takes care to test framing effects given the existence of more than one frame. I therefore propose the following research question:

RQ3: To what extent does framing research attend to a mixed-frames approach?

And lastly, Borah correctly addresses the possibility of mediating and moderating effects. Similar to the need to test multiple, even competing frames at the same time, 
it is necessary to acknowledge that the interaction of framing effects may posses mediating and moderating properties; frames that may not cause direct causal effects, but rather, play a role in indirectly affecting a subject. Mediators play a role in this, as a mediator is a variable that accounts for the relation between the independent and dependent variable. Broadly, a moderator is a variable that impacts the direction and/or the veracity of a correlative or causal relationship between an independent and dependent variable. Previous work has examined moderators in framing effects (Miller \& Fagley, 1991), finding that while framing has an effect on individuals, that effect is impacted by specific preferences, desires, or opinions (mediating effects) of the individuals under study. Individuals are not passive, and as such, framing effects are not always perfectly causal.

I therefore propose the following research question:

RQ4: To what extent does framing research attend to mediators and moderators in framing effects? 


\section{Beyond Borah: Accounting for Power Relationships}

While Borah's (2011) initial work takes some necessary steps to address the status of framing literature, several improvements can be made. Firstly, the study can be operationalized to test more of the specifics of Scheufele's (1999) criticism. Borah asks to what extent current research investigates frame building. However, the current study will ask to what extent current research investigates not only frame building, but frame setting, individual level effects, and feedback effects.

\begin{tabular}{|c|c|c|}
\hline & Frame Building $\rightarrow$ & Frame Setting \\
\hline$\uparrow$ & Feedback Effects & $\leftarrow$ Individual Level Effects \\
\hline
\end{tabular}

Additionally, however, several authors critical of the role academia plays in society offer necessary criticism to the way research is conducted, and to the types of questions research is asking.

Lastly, in the interest of integrity, research ought be criticized to ask who garners value from framing research. Often, logistical and other concerns limit the ability of the academy to explore necessary and critical research questions. In examining framing research, it is important to ask who is being researched, and to what end. Michael Warner's (2002) work, "Publics and Counterpublics" requests delineation between society at large, and groups within society that are underrepresented or excluded from the public at large. Marginalized populations can exist within a broader population. Due to the unique circumstances of these 
communities, research questions do not always adequately address their circumstances. Research that exclusively focuses on the majority may miss many significant issues facing members of these "counterpublics." Any academic attempt to address the status of the literature should be concerned with whether or not the academy is paying sufficient attention to these groups, less the implications of research fail to serve or provide value for those in most need of assistance.

Consistent with authors who have called for a critical examination of the role power plays in framing research, Carragee and Roefs (2004) critique developments in framing research. Framing research fails to grapple with the relationship between media frames and the broader issues of political and social power. The authors isolate that such failure stems from numerous factors including, conceptual problems in the definition of frame, the inattention to frames sponsorship, the failure to examine framing contests within wider political and social contexts, and the reduction of framing to a form of media effects. In this explanation is an argument in favor of understanding the social construction of meaning. Since frames change over time (both from journalists and media, as well as within the public more broadly) it is important for conceptualizations of the framing process to pay attention to how framing interacts with social constructions.

Power plays the most principal role in such structures. This is critical, because the reduction of frames to specific story topics, attributes, or issue positions ignore the ways in which frames themselves construct particular meanings. It also ignores the way frames influence the ways issues are perceived, and the way the 
same frame, or framing movements/devices apply to a multiplicity of discourse objects and events.

Carragee and Roefs argue for framing research to be linked to the political and social questions concerning power central to the media hegemony thesis, and illustrate this focus by exploring how framing research can contribute to an understanding of the interaction between social movements and the news media. This requires a deeper examination of frame sponsorship and the influence that has on framing content. Carragee and Roefs argue that economic and cultural assets of elites provide substantial resources involved in the shaping of journalistic frames. This plays as a force to strengthen cultural hegemony of the status quo; it reinforces the existing distribution of power. When framing research focuses so intently on media effects, it narrows the scope of scholarship in a way that prevents counterhegemonic examinations of the role power plays in framing, according to Carragee and Roefs.

Carragee and Roefs are careful to point out that framing research can serve a better purpose. Framing research may be a valuable tool in examining the dominant ideology propagated by mass media, allowing an exposure of ideological construction consistent with interests of powerful elites. This only occurs, however, when framing and reasoning devices used to produce meaning are linked by framing research beyond the utterance and effects of media products. Framing research is also necessary, argue Carragee and Roefs, to understand the effect dominant ideological frames have on the audiences of media. To understand why the public at large accepts (and sometimes rejects) hegemonic discourse products in 
certain instances provides traction to criticize or enhance the effects of maintaining public consent with the status quo. The way then that members of the public organize and act as a result is linked to framing as well. Social movements are engaged with a struggle to win a battle of framing, to undermine dominant framing practices, and change public approach and understanding of issues. Carragee and Roefs argue that future research should focus on the framing power of social groups, of media and elites, and the power asymmetry between the two groups likely responsible for the discrepancies in the power of said framing effects.

With this criticism in mind, I propose the following research questions: RQ 5(a): What sorts of populations are studied most frequently in framing research?

RQ 5(b): Are certain institutions prioritized in framing research above others?

It will be valuable to address these questions. There is significant risk that framing studies using experimental design occurs not because of the potential gains from the research, but rather from convenience, potentially resulting in the over study of certain populations and institutions, and the understudy of others. This passive dismissal harms framing research by failing to be relevant and valuable for all individuals, and also, means that framing research is rarely presented with the challenge of researching relationships of power, or of structural concerns. This means that framing research is not accountable to have explanatory power for members of a counterpublic, and as such, may not provide explanatory power as scholars believe. 


\section{Operationalizations}

\section{Research Question 1}

The following section starts with each research question, explains how we operationalized the terms and variables described in the research question, and offers examples of such content. Lastly, the specific code options are listed to show exactly what choices coders could make in regards to the research question. For further clarification on any of the coding, please refer to the Coding Manual in the Appendix.

RQ1(a): Is there a dominant paradigm of framing research?

RQ1(b): In framing research, what is most common: the study of unique frames, or the study of theory-based frames?

The first research questions seek to uncover if a dominant paradigm in framing exists, in order to address the fundamental tension between D’Angelo (2002) and Entman (1993). In order to do so, it is important to see how often researchers use each other's work in order to further the study of framing. To test this, coders were asked to identify if the frames under study in any given article were "unique" or "theory based.

To test this, a "Basis of Frame" category was created for each study examined. The Basis of Frame describes the theoretical and/or methodological base of the frame. A "theory" frame originates explicitly from prior literature. A "unique" frame originates from the material being studied, or in some other way is nonattributable to prior research. Coders were asked to pay special attention to both the literature review and methodology sections of articles to determine if the study 
being coded had been designed to test a previously studied frame, or if the existence of a new frame came about uniquely in virtue of the results of the study.

Borah (2011) examined whether researchers are creating their own frames for their studies or whether they are using frames from the literature. She labels these "unique" and "consistent frames", arguing that unique frames are ones that researchers regard as emerging uniquely from a study. For example, Coleman's 2013 analysis of news coverage of an ancient skeleton discovered in North America revealed unique frames of simulacra and synecdoche that framed the skeleton as Jean-Luc Picard, a fictionalized and futuristic Starfleet commander. Additionally, frames about war and battle contests (highlighting conflicts between tribal members and scientists), science versus religion (with science elevated to a superior status), the rights and legitimacy of key stakeholders (tribal members, scientists, the courts, and the federal government) as legal and moral, and "progress" as a description of stakeholder platforms all emerged from study of media text, without previous authorship describing and documenting the existence of said frames.

Theory frames (what Borah refers to as "consistent frames"), however, allow the researcher to invoke framing literature when designating and measuring frames. For example, Coleman, Hartley and Kennamer (2006) assert that common frames seen in prescription drug news coverage include costs, benefits and drawbacks, frames previously investigated which they, in turn, adopted for their 2006 framing study.

We therefore asked coders to assess each study based on the following categories: 
Figure 2 - Basis of Frame Codes:

- 1 = Theory Based

- $\quad 2$ = Unique (topic) Based

- $\quad 3=$ Both are used

- $88=$ Other or Don't Know

$-99=\mathrm{N} / \mathrm{A}$

\section{Research Question 2}

RQ2(a): To what extent does framing research attend to frame building? RQ2(b): To what extent does framing research attend to frame setting? RQ2(c): To what extent does framing research attend to individual level effects?

RQ2(d): To what extent does framing research attend to feedback effects?

Research question 2 attempted to test Scheufele's (1999) model, in which he creates four mutually exclusive and exhaustive categories: frame building, frame setting, individual level effects, and feedback effects. The phrase "attend to" used in the research question refers to the "framing effects approach" category of the coding manual. Framing Effects Approach refers to the specific framing effect being studied, and asks the coders to locate where in Scheufele's model the framing effect is occurring. Essentially, the category asks the coders to document what the research effect is trying to prove.

Frame building research looks at how frames are formed; the processes that influence the creation or alteration of frames. For example, Fryberg, Stephens, Covarrubias, Markus, Carter, Laiduc, and Salido (2012) examine the role that geography plays in correlation to media frames. Researchers employed a content analysis of Arizona based, as well as nationally circulating, newspapers' coverage of a proposed Arizona state immigration law, in order to determine if there was a 
correlation between geography, and political bias of a given publication, and the way the news media framed the issue of immigration, and value judgments placed on actual immigrants themselves.

Frame setting research looks at how frames enter, or become part of, the public/societal arena. Rather than looking at what sorts of things effect frames, this category looks at how frames effect or impact society. For example, Barry, Brescoll, and Gollust (2013) argue that political actors recognize the power of framing an issue in terms of personalized examples and casual stories to shape public opinion. Their study examines the frequency in which news media frame the problem of childhood obesity by relying on individual depictions of obese children to portray the problem in actual news study, and the way those stories were likely or unlikely to effect audiences.

Individual level effects research examines the effects of frames and framing on individual's attitudes, beliefs, knowledge, etc. Unlike the framing effects isolated above, individual effects research necessitates human subjects, and the cognitive processing involved when exposed to, or interacting with, a frame. For example, Aday's (2010) study examining the effect of visual frames about warfare on individuals' perception of a news story serves well as this example. In the piece, individuals were exposed to one of a three conditions: a control, a battle frame, and a casualty frame. In each condition, subjects were asked to read a fake newspaper story about the United States' invasion of Iraq. In the control group, individuals only read the text of the story. In the battle frame condition, the same text was accompanied by images of soldiers succeeding in battle, as opposed to the casualty 
frame, where individuals were exposed to the same text paired with images of US soldiers wounded, and bleeding, on the battlefield. Both before and after exposure to the fake news story, individuals took a short survey on their attitudes, emotions, and support for the United States' invasion of Iraq to examine what effect the visual frames had on the meaning of the newspaper article.

Feedback effects research investigates the process wherein frames affect individuals participating in frame building or frame setting. This category makes the model fully explanatory, as it allows a framing effect be traced from initial creation of the frame, to the (re)creation of new, or perpetuation of existing, frames.

Coding instructions for Framing Effects Approach were as follows:

Figure 3 - Framing Effects Approach

A1 - Framing Effects Approach 1 CODES

- $\quad 1$ = Frame Building

- $\quad 2=$ Frame Setting

- $\quad 3=$ Individual Level Effects

- $\quad 4=$ Feedback Effects

- $\quad 88=$ Other or Don't Know

- $\quad 99=\mathrm{N} / \mathrm{A}$

A2 - Framing Effects Approach 2

CODES

- $\quad 0=$ No Second Approach

- $\quad 1=$ Frame Building

- $\quad 2=$ Frame Setting

- $\quad 3=$ Individual Level Effects

- $\quad 4=$ Feedback Effects

- $88=$ Other or Don't Know

- $\quad 99=\mathrm{N} / \mathrm{A}^{1}$

If the author uses multiple approaches, to examine multiple effects, then code the second approach exactly as the above.

- If there is no second approach, or no second effect under study, code as "0" (No Second Approach) and immediately code the next section (Framing Effects Approach 3) as "0" (No Third Approach). 
(Figure 3 continued)

A3 - Framing Effects Approach 3

CODES

- $\quad 0=$ No Third Approach

- $\quad 1=$ Frame Building

- $\quad 2=$ Frame Setting

- $\quad 3=$ Individual Level Effects

- $\quad 4=$ Feedback Effects

- $88=$ Other or Don't Know

- $\quad 99=\mathrm{N} / \mathrm{A}$

AExtra - More than 3 Approaches

CODES

- $\quad 0=$ Three or Less Approaches

- $\quad 1=$ More than Three Approaches

- $\quad 88=$ Other or Don't Know

- $\quad 99=\mathrm{N} / \mathrm{A}$

Coders were given up to three opportunities to code Framing Effects Approach in the case of multiple approaches being examined in the same published study. Occurrences of such were rare.

\section{Research Question 3}

RQ3: To what extent does framing research attend to a mixed-frames approach?

Framing research ought have the ability to test effects in a way that does not suffer too greatly from threats to external reliability. There is a tension between wanting to isolate a single frame, to test its effect ceteris paribus. However, in doing so, there is a risk of low external validity. That is to say, frames are present in a variety of situations and contexts, and as such, in the real world outside the laboratory, it is unlikely for an individual to experience framing effects in such a vacuum. Scholars have argued that many decisions individuals make are a choice between competing values, or competing frames (Sniderman \& Theriault, 2004), 
and, that value conflict is a necessary link between issue framing and political judgment (Borah, 2011).

A mixed frames approach to study, then, is a specific type of experimental design used to test the effect of frames. Mixed frames studies take Condition ' $A$ ' and Condition ' $\mathrm{B}$ ' and combine them into a third 'A/B' Condition (see below).

\section{Table 1 - Mixed Frames}

\begin{tabular}{|l|l|}
\hline $\begin{array}{l}\text { Group 1: } \\
\text { Control Group (No frame exposure) }\end{array}$ & $\begin{array}{l}\text { Group 2: } \\
\text { Exposed (exclusively) to Frame A }\end{array}$ \\
\hline $\begin{array}{l}\text { Group 3: } \\
\text { Exposed (exclusively) to Frame B }\end{array}$ & $\begin{array}{l}\text { Group 4: } \\
\text { Exposed to BOTH Frames } \\
\text { (i.e. Frame A \& Frame B) }\end{array}$ \\
\hline
\end{tabular}

For the current study, coders were asked to identify the methodology used by given authors to investigate their primary research question. After checking for methodology, coders then would decide whether or not a mixed frames approach was employed. It is important to note that for all articles that were not a framing effects experiment, coders coded the mixed frames approach category as 99 (N/A not an experiment). When coders selected " $0=\mathrm{No}$ ", it means that while the article was an experiment, and the researcher had the ability to test mixed frames, the researcher failed to do so. Aday (2010) serves as a good example here, for while individuals in Aday's study were exposed to a control, a battle frame, and a casualty frame, no group was exposed to both the battle and casualty frames. Such an article would have been coded as " $0=\mathrm{No}$ ". Coding instructions were as follows: 
Methodology Coding

This section deals primarily with the methods used by the author to investigate his/her primary research question, and the theoretical framework the articles author is using.

Figure 4 - Method Coding Method - Primary research method

CODES

- $\quad 1=$ Content Analysis

- $\quad 2$ = Survey (non-experimental

- $\quad 3=$ Experiment

- $\quad 4=$ Theory Building

- $\quad 5=$ Meta-Analysis

- $6=$ Multiple Methods

- $\quad 88=$ Other $^{2}$

DECISION RULE 2

If " 4 " $\rightarrow$ Code all following as "99"

If else $\rightarrow$ Continue

Figure 5 - Mixed Frames Approach

Mixed - Mixed frames approach (experiments only)

CODES

- $\quad 0=$ No

- $1=$ Yes

- $\quad 88=$ Other or Don't Know

- $\quad 99=\mathrm{N} / \mathrm{A}$ (not experiment)

NOTES

- Only code experimental articles as “0" or " 1 "; code all non-experiments as "99"

\section{Research Question 4}

RQ4: To what extent does framing research attend to mediators and moderators in framing effects?

Positioned as footnote taken from the coding manual: Content analysis includes research that compares a content analysis to a 'standard' (e.g. comparing how the media portrays intimate partner violence to epidemiological estimates about the occurrence of said portrayals) 
For the purposes of this study, mediators and moderators are considered processes. A "process" in the context of this study is the investigation of an underlying phenomenon, such as what causes X to have an effect on Y. "Mediators" are mechanisms through which a predictor influences an outcome variable. Mediation in its simplest form represents the addition of a third variable to the $\mathrm{X} \rightarrow$ Y relation, whereby $X$ causes the mediator, $M$, and $M$ causes $Y$, so that $X \rightarrow M \rightarrow Y$. For example, while United States citizens may be a certain amount likely to acquire mass media information. However, it may be the case that an individual's income level mediates the amount and speed of mass media information acquired (those with greater income are more likely to acquire mass media information more rapidly than those with lower income). In this example, income is a mediator that influences the phenomena in question.

"Moderators" are variables that alter the relationship between a predictor variable and an outcome variable. Questions involving moderators' influence address when, or for whom, a variable most strongly predicts an outcome variable. In other words, moderators can affect the direction or intensity of an outcome.

Tewksbury et al., (2000) is a good example of studying mediators in framing research. In their study, researchers demonstrate that news frames (as a result of journalists' choices, emphasis, etc.) do not directly influence a passive audience, but rather, interact with advocacy frames, which individuals possess, to then influence audience perception of a political issue. Igartua and Cheng, (2009) research moderating effects from news frames on immigration. The researchers demonstrate that the framing effect of newspapers covering immigration issues differs depending 
on if the hypothetical immigrants are Latino or Moroccan, as it relates to potential economic contribution of immigration, or potential crime growth, as frames applied to potential immigrants.

Coding instructions were as follows:

Figure 6 - Process Coding

$\mathrm{P}$ - Processes

CODES

- $\quad 0=$ None

- 1 = Mediators

- $\quad 2=$ Moderators

- $\quad 3=$ Both Mediators and Moderators

- $\quad 88=$ Other or Don't Know

- $\quad 99=\mathrm{N} / \mathrm{A}$

NOTES

- $\quad$ Code "0" IFF the research looks at framing effects, i.e. if it would have been possible to explore mediators/moderators, otherwise code "99"

\section{Research Question 5}

RQ 5(a): What sorts of populations are studied most frequently in framing research?

RQ 5(b): Are certain institutions prioritized in framing research above others?

RQ 5(c): To what extent does framing research attend to the organizational/political arena?

RQ 5(d): To what extent does framing research attend to the public/societal arena?

RQ 5(e): To what extent does framing research attend to the news media arena?

RQ 5(f): To what extent does framing research attend the counter public arena?

Research question 5 addresses the concerns of Carragee and Roefs (2004),

and Warner (2002). The arena category was created to differentiate the source of a frame; who is doing the framing and/or whom the frame is affecting. The "Organizational / Political" arena consists of organizations that have an interest in 
altering, controlling or changing the public discourse. This also includes individuals acting on behalf of an organization (e.g. The President speaking on behalf of the "Office of the President," a corporate spokesperson or CEO, etc.). Corcoran (1994), for example, examines the framing present in presidential concession speeches, made by candidates who have lost the United States presidential elections.

The "Public / Societal" arena consists of individuals, either independently or as an aggregate, who are also acting independent of an organization and/or as a mass public. Joslyn and Haider-Markel (2002) offer a good example of this in their study on social security and physician assisted suicide. The researchers studied respondents exposed to opposing frames on the two issues of social security and physician assisted suicide, to examine the extent that these frames are present in public consciousness.

The "News Media" arena includes all media products and the producers of media products (i.e., journalists) who are not functioning as organizational or political actors (for example, if a journalist giving an interview on TV as a representative of her organization, and its business practices, then it would be the organizational/political arena, not media). Jasperson, Shah, Watts, Faber, and Fan (1998) examine dominant frames present in media coverage of the federal budget deficit of the United States, as it relates to public opinion polls, to examine the role media plays in creating specific frames about economic issues.

The "Counter Public" arena is composed of discourse and discourse products (and the agents who create these products) aimed at a public that perceives themselves as excluded from the mass public. Ho and Rolfe (2010) offer an example 
of such framing, examining the way gay rights activists employ a civil rights frame as a strategy for furthering their political agenda.

Coding instructions were as follows:

Arena and Level Coding

There are three parts to the arena and level coding: the source of the frame (arena), the location of the frame (level), and the orientation of the frame in the research (independent or dependent variable).

Figure 7 - Frame Arena Coding F1A - Frame 1 arena

CODES

- $\quad 1=$ Organizational $/$ Political

- $\quad 2=$ Public $/$ Societal

- $3=$ Media

- $\quad 4=$ Counter-Public

- $\quad 88=$ Other or Don't Know

- $\quad 99=\mathrm{N} / \mathrm{A}$

DECESION RULE 3

If "99" $\rightarrow$ Code all following as "99"

If else $\rightarrow$ Continue

F2A - Frame 2 arena

CODES

- $\quad 0=$ No Second Frame

- $\quad 1=$ Organizational $/$ Political

- $\quad 2=$ Public / Societal

- $3=$ Media

- $\quad 4=$ Counter-Public

- $\quad 88=$ Other or Don't Know

- $\quad 99=\mathrm{N} / \mathrm{A}$

F3A - Frame 3 arena

CODES

- $\quad 0=$ No Third Frame

- $\quad 1=$ Organizational $/$ Political

- $\quad 2=$ Public / Societal

- $3=$ Media

- $\quad 4=$ Counter-Public

- $\quad 88=$ Other or Don't Know

- $99=\mathrm{N} / \mathrm{A}$ 
(Figure 7 continued)

FExtra - More than 3 types of frame

CODES

- $\quad 0=$ Three or Less Frame Types

- $\quad 1=$ More than Three Frame Types

- $\quad 88=$ Other or Don't Know

- $\quad 99=\mathrm{N} / \mathrm{A}$

Coders were given up to three opportunities to code Framing Effects Approach in the case of multiple approaches being examined in the same published study.

Occurrences of such were rare.

Additionally, in the interest of being thorough, two more coding categories where created. As a matter of housekeeping, we wanted to track how often frames were treated as independent or dependent variables. Coding instructions were given as follows:

Figure 8- Frame Variable Coding F1V - Frame 1 DV or IV

CODES

- $\quad 1$ = Independent Variable

- $\quad 2$ = Dependent Variable

- $88=$ Other or Don't Know

- $\quad 99=\mathrm{N} / \mathrm{A}$

F2V - Frame 2 DV or IV CODES

- $\quad 0=$ Not Second Frame

- $\quad 1=$ Independent Variable

- $\quad 2$ = Dependent Variable

- $\quad 88=$ Other or Don't Know

- $\quad 99=\mathrm{N} / \mathrm{A}$

F3V - Frame 3 DV or IV

CODES

- $\quad 0=$ Not Third Frame

- $\quad 1=$ Independent Variable

- $\quad 2$ = Dependent Variable

- $\quad 88=$ Other or Don't Know

- $99=\mathrm{N} / \mathrm{A}$ 
(Figure 8 continued)

FExtra - More than 3 types of frame

CODES

- $\quad 0=$ Three or Less Frame Types

- $\quad 1=$ More than Three Frame Types

- $88=$ Other or Don't Know

- $\quad 99=\mathrm{N} / \mathrm{A}$

Coders were given up to three opportunities to code framing variable in the case of multiple approaches being examined in the same published study. Occurrences of such were rare.

Lastly, we also wanted to know what sorts of texts are being studied. In order to make sure framing research accounts for a variety of study, we sought to differentiate the location where any given frame is manifest. We created three categories: cognitive, discourse, and textual to determine what sorts of texts were studied by framing researchers. The "cognitive" level includes all mental constructs; that is, it includes frames that guide the way individuals think about an issue, topic, etc. The "discourse" level includes frames emerging from active discourse (e.g. a debate, a conversation, an online open forum, etc.). The "textual" level, or discourse product level, includes all static and/or unidirectional information (e.g. a speech, newspaper article, YouTube video, etc.). This allows us to verify that framing research is studying a sufficiently diverse range in the kinds of conversations, texts, or rhetorical objects studied by framing scholars. 
Coding instructions were given as follows:

Figure 9 - Frame Level Coding

F1L - Frame 1 level

CODES

- $\quad 1=$ Cognitive

- $\quad 2$ = Discourse (interactive)

- $\quad 3=$ Text (static)

- $\quad 88=$ Other or Don't Know

- $99=\mathrm{N} / \mathrm{A}$

F2L - Frame 2 Level

CODES

- $\quad 0=$ No Second Frame

- $1=$ Cognitive

- $\quad 2=$ Discourse (interactive)

- $\quad 3=$ Text (static)

- $\quad 88=$ Other or Don't Know

- $\quad 99=\mathrm{N} / \mathrm{A}$

F3L - Fame 3 level

CODES

- $\quad 0=$ No Third Frame

- $1=$ Cognitive

- $\quad 2=$ Discourse (interactive)

- $3=$ Text (static)

- $\quad 88=$ Other or Don't Know

- $\quad 99=\mathrm{N} / \mathrm{A}$

FExtra - More than 3 types of frame

CODES

- $\quad 0=$ Three or Less Frame Types

- $\quad 1=$ More than Three Frame Types

- $\quad 88=$ Other or Don't Know

- $\quad 99=\mathrm{N} / \mathrm{A}$

Coders were given up to three opportunities to code framing level in the case of multiple approaches being examined in the same published study. Occurrences of such were rare. 


\section{Methodology}

\section{Sample}

The unit of analysis for this study was peer-reviewed journal articles on framing from 2000 to 2014. We wanted to expand the timeframe that Borah (2011) used. To do so, we expanded her study by four years, starting with the year immediately preceding the start of this study, and moving backwards to the year 2000. Following the methodology of Borah, we had a team of undergraduate communication students search a set of databases for articles containing either the terms "framing" or "frames" or both. We identified which journals were relevant by following Borah's example, using every journal identified as a "communication journal" in the Journal Citation Report, the Institute for Scientific Information's (ISI) Social Sciences Citation Index (Web of Knowledge).

To check for journals from outside Communication studies, a second sampling method was used to supplement the ISI list. Keyword searches in the following electronic databases: the ISI Social Sciences Citation Index (Web of Science), PsychINFO, Communication Abstracts, Sociological Abstracts, and ProQuest Research Library, were used to gather the remaining journals. We then identified from those articles 3350 journals (or journal-like publications), which appeared to have published at least one article about framing during the time period we investigated. Of those, 315 were only printed in foreign language journals, and 94 were completely unavailable to us via PSU/Summit Databases. This left a revised total of 2942 journals. 
From there, we used the Portland State University Library website to search for each given journal. Once we found the journal, we used whichever database allowed us to search its content (EBSCOhost, Wiley, etc.). Searching all articles published from 2000-2014, we did a text search for the same terms ("frames" or "framing") and collected every citation into a Zotero group account. Zotero is a free program that allows members of a group to make note of, and categorize, bibliographic information when reading an article online. The program (Zotero) then consolidates all the information, and organizes the information, which can be exported to programs such as Microsoft Excel in order to systematically view all the data. This gave us an initial pool of 8705 articles that met the search criteria. Unfortunately, the program is not perfect, and did bring back some results that were not ultimately relevant for study. The pool was narrowed to 7965 (91\% of the initial search) by cleaning the data. Articles that had been saved twice in Zotero (as a result of being published multiple times, or other overlap) and articles that did not have a documented author credited were eliminated to ensure accuracy.

\section{Coding}

The remaining articles $(\mathrm{N}=7965)$ were assigned random numbers in order to choose a sample randomly. Four coders (three undergraduate students and one graduate student, all who earned college credit for the work) were assigned an initial set of 100 articles that had been randomized in order to test the coding Manual. Coders reported that about $20 \%$ of the articles met the study's criterion of centering on framing theory and/or research, with $80 \%$ of the articles judged as invalid. Rejected articles included book reviews, articles that referred to 
"framework" and "frames of reference" rather than "frame," and engineering or biological frames, rather than message or cognitive frames. Ultimately, these numbers had no bearing on the final sample size. They were used rather as a way to make sure that the coding manual was written well, to troubleshoot any directions/instructions given to coders, and to get a rough estimate of the scope of the project. None of the 100 articles coded for this part of the study were included in the final data or results.

We estimated that $20 \%$ of 7,965 articles would yield 1,593 valid articles. We determined that a sample size of 316 would yield a confidence interval of 2.5 and a confidence level of $95 \%$.

To double-check whether $20 \%$ of articles accurately reflected article validity, a fifth coder was assigned a random sample of articles to assess whether the sample met the initial criterion of framing.

The coder reviewed 316 articles and reported that 69\% (n=219) failed to meet the criterion and $15 \%$ were valid $(n=45)$. The coder marked the remaining $16 \%$ of articles $(n=51)$ as indeterminate, meaning their validity would need to be checked by another coder.

Armed with this information, we determined that between 15 to 20 percent of the pool of 7965 articles would be central to framing, or, 1195 to 1593. A sample size that would yield a confidence interval of 5 and a confidence level of $95 \%$ would include 291 to 310 articles. We therefore coded 326 articles.

Articles were coded for aspects outlined in the operationalizations section above. Records were kept of the coder, the date coding occurred, whether or not the 
article was appropriate (if it contributed to framing research), the article's methodology, the basis of the frame under study (theory or unique based), the type of frame, if the author examined any mediating or moderating effects, the arena or source of the frame (which subject, or subjects, were under study as creating or producing frames), the level at which the frame was present (individual level micro effects, to broader societal macro effects), whether the frame being studied was treated as a dependent or independent variable, as well as the articles place in Scheufele's four-phase model. For details about coding, see the Coding Manual. From there, data was entered into SPSS to compute the following statistical analysis.

\section{Inter-Coder Reliability}

Inter-coder reliability was tested using Krippendorff's Alpha reliability estimate. Krippendorff's alpha measures agreement between coders by examining instances where multiple individuals code a set of units of analysis in terms of the values a given variable. So for every variable created for the study, a range of values was presented as potential coding options.

Krippendorff's alpha was tested for each potential coding decision. Alpha for the methodology coding was .824, for the mixed frames approach was .749, for the basis of the frame (theory or unique) was .730. For the mediators and moderators question, coders were unreliable, as Krippendorff's alpha was reported -.023. Alpha for the first frame arena, was 1.000, the second arena was .734, and .543 for the third arena. Alpha for the first frame level was 1.000, alpha was .682, for the second frame level and .513 for the third frame level. Alpha for the frame's variable status was .814 for the first frame variable, .622 for the second frame variable, and .553 for 
the third frame variable. There was a reported .563 for coding if there were more than 3 frames studied in a given article. Krippendorff's alpha was reported as .765 for inter-coder reliability for the first framing effect approach used in any given article. Alpha was reported .582 for the second approach, and .452 for the third approach employed by an author. Alpha was .250 for whether or not there were more than 3 approaches utilized by an author for a given study.

A note on reliability: most of the reported alphas are within acceptable range of inter-coder reliability. Agreement quickly decreases as coders evaluated a second, or third frame in the study. This is likely due to disagreement over what constitutes as primary, secondary, or tertiary frame. If a study examined more than one, or two, or even three, frames, coders were asked to code the frames as they were reported chronologically. As a result, more disagreement arose.

Additionally, there may have been confusion on what constituted multiple frames. For example, Fryberg et al. (2012) examined how immigrants are framed, using a content analysis of newspaper articles to identify language choice that can be coded as supportive or against immigration. One coder may have reported on the framing of an immigrant as frame one, and then coded " $0=$ No second frame" under the following arena, level, and variable coding. However, another coder may have considered the first frame to be positive framing of an immigrant, coded it as such, and the second frame as negative framing of an immigrant, and coded it as such. This would account for the perfect agreement in terms of the first frame arena, variable, and level coding, as well as the disagreement on the second frame arena, level, and variable coding. 
The takeaway here is that while reliability for many of those measures looks bleak, it is not exactly so dire as such. The very high level of agreement on the first categories suggests that coders all could identify the arena, level, and variable status of a frame. They disagreed, however, on how to report the number of frames in a given article. This should be interpreted to mean that the substantive aspects of the coding (where the frame originates from, where the frame is manifest, if it is an independent or dependent variable) are all reliable measures. 


\section{Results}

Of the articles coded for the study, $77.4 \%(\mathrm{~N}=1119)$ were not adequate for use. While the articles contained at least one use of the words "frames" or "framing", the articles did not in any way contribute to framing research. However, $22.5 \%$ $(\mathrm{N}=326)$ of the articles did meet that basic criterion, and were coded for further information.

Of those valid articles, the most common type of methodology employed by framing scholars was content analysis, a total of 174 (53.4\%) articles. The second most common was experiments at 68 (20.9\%), followed by multiple methods (9.8\%), survey (non-experimental) at $20(6.1 \%)$, other $17(5.2 \%)$, and least of all were theory-building articles at 14 (4.3\%). Of applicable articles, $40.1 \%$ reported treating frames as an independent variable, while 59.2\% treated them as dependent variables.

To answer Research Question 1, RQ1(a): Is there a dominant paradigm of framing research? RQ1(b): In framing research, what is most common: the study of unique frames, or the study of theory-based frames?, articles were coded to see if they used frames based in previous academic study (theory-based), or found unique frames (unique) or both. Of the 326 articles coded, 58.6\% ( $\mathrm{N}=191)$ studied theorybased frames, 33.4\% ( $\mathrm{N}=109)$ found unique frames, and 4.9\% ( $\mathrm{N}=16)$ studied both.

To answer Research Question 2, RQ2(a): To what extent does framing research attend to frame building? RQ2(b): To what extent does framing research attend to frame setting? RQ2(c): To what extent does framing research attend to 
individual level effects? RQ2(d): To what extent does framing research attend to feedback effects?, articles were coded for the first, and if applicable, second and third framing approach (in accordance with Scheufele's (1999) four-phase model). For the first approach used in any given article, 44\% (N=142) were concerned with frame building, followed by 31.9\% (N=103) about frame setting. Only 18.9\% (N=61) of the articles focused on individual level effects, and less than $1 \%$ of articles $(\mathrm{N}=3$ ) focused at all on feedback effects.

Slightly more than half of the articles did not use a second framing effects approach (55.8\%, $\mathrm{N}=182)$. Of the 135 articles that did employ a second framing effects approach, results reported $40 \%(\mathrm{~N}=54)$ were concerned with frame building, followed by $37.8 \%(\mathrm{~N}=51)$ about frame setting. Only $22.0 \%(\mathrm{~N}=30)$ of the articles focused on individual level effects, and none focused at all on feedback effects.

Fewer articles reported a third framing effects approach studied (N=63). Of those which employed a third framing effects approach results reported 52.4\% $(\mathrm{N}=33)$ were concerned with frame building, followed by $46 \%(\mathrm{~N}=29)$ about frame setting. Only one article focused on individual level effects, and none focused at all on feedback effects. The majority $(77.5 \%, \mathrm{~N}=251)$ of articles did not report a third framing effects approach. The vast majority $(90.1 \%, \mathrm{~N}=292)$ reported three or less framing effects approaches studied, with 22 articles (6.8\%) reporting more than three framing effects approaches studied.

To answer Research Question 3, RQ3: To what extent does framing research attend to a mixed-frames approach?, articles were coded to see if they used a mixed- 
frames approach, or not. Of the articles studied 3 , 71.5\% (N=229) of articles were not experiments, and as such, were not applicable to be coded as such. Of the 91 articles that used experiments that could have employed a mixed-frames approach, $54.9 \%$ $(\mathrm{N}=50)$ did not use a mixed-frames approach, while $45.1 \%(\mathrm{~N}=41)$ did.

To answer Research Question 4, RQ4: To what extent does framing research attend to mediators and moderators in framing effects?, articles were coded to see if the author reported any mediators or moderators in their findings. Of the 260 articles that could have reported any mediators or moderators ${ }^{4}, 93.5 \%(\mathrm{~N}=243)$ did not report on them. Only 3.4\% ( $\mathrm{N}=9$ ) reported on moderators (exclusively), $2.3 \%$ $(\mathrm{N}=6)$ reported on mediators exclusively, and $0.8 \%(\mathrm{~N}=2)$ reported both mediators and moderators.

Lastly, to answer Research Question 5, RQ 5(a): What sorts of populations are studied most frequently in framing research? RQ 5(b): Are certain institutions prioritized in framing research above others? RQ 5(c): To what extent does framing research attend to the organizational/political arena? RQ 5(d): To what extent does framing research attend to the public/societal arena? RQ 5(e): To what extent does framing research attend to the news media arena? RQ 5(f): To what extent does framing research attend the counter public arena?, each frame was coded for its

\footnotetext{
${ }^{3}$ Here the total number of articles coded for a mixed-frames approach is a bit less $(\mathrm{N}=320)$. This is because while there was only the options of " $0=$ No," " $1=Y e s, "$ "88=0ther," "99=N/A," six articles returned with codes " 3 " and "4", and as such, were discarded for the purposes of this statistical analysis. 4 Of the 326, 66 articles were coded as "99=N/A" indicating that it would not have been applicable for the author to report a mediating or moderating variable, as the author was not investigating a causal relationship between an independent and dependent variable.
} 
arena in order to differentiate the source of a frame (who is doing the framing and/or whom is being affected by the frame), the organizational / political arena (consisting of organizations that have an interest in altering, controlling or changing the public discourse), the public / societal arena (consisting of individuals, either independently or as an aggregate, who are also acting independent of an organization and/or as a mass public), the news media arena (including all media products (i.e., news products) and the producers of media products (i.e. journalists) who are not functioning as organizational or political) and the counter public arena (composed of discourse and discourse products (and the agents who create these products) aimed at a public that perceives themselves as excluded from the mass public).

Articles were coded for the first, and if applicable, second and third framing arena. For the first framing arena, $61.5 \%(\mathrm{~N}=187)$ were from the news media arena, followed by the public / societal arena with $19.1 \%(\mathrm{~N}=58)$, the organizational / political arena reported $15.5 \%(\mathrm{~N}=47)$, and the least being the counter public arena with only .04\% (N=12).

Half of the articles did not report a second framing arena (50.1\%, N=156). Of the 151 articles that did employ a second framing arena, $70.2 \% \%(\mathrm{~N}=106)$ were reported from the news media arena, followed by $12.6 \%(\mathrm{~N}=19)$ from the public / societal arena. $11.9 \%(\mathrm{~N}=18)$ of the articles were from the organizational / political, and $5.3 \%(\mathrm{~N}=8)$ came from the counter public arena.

Fewer articles still reported a third framing arena studied, $28.1 \%(\mathrm{~N}=89)$. Of the 89 articles which employed a third framing arena results reported $79.8 \%$ 
$(\mathrm{N}=71)$ were from the news media arena, followed by $14.6 \% \%(\mathrm{~N}=13)$ from the organizational / political arena. Only $3.4 \% \%(\mathrm{~N}=3)$ of the articles were from the counter public arena, and 2.2\% ( $\mathrm{N}=2)$ were from the public / societal arena. Most (71.9\%, $\mathrm{N}=228)$ ) of articles did not report a third framing arena. The majority (79.6\%, $\mathrm{N}=253)$ reported three or less framing arenas studied, with 65 articles (20.4\%) reporting more than three framing effects approaches studied. 


\section{Discussion}

Framing research seems at an interesting crossroads. The above statistical analysis presents a crucial first step in understanding the current status of, and necessary future direction of framing research. As to whether or not framing has a dominant paradigm, the answer seems unclear. The above analysis was conducted from 2000 to 2014 , and found that 58.6\% (N=191) studied theory-based frames, and $33.4 \%(\mathrm{~N}=109)$ found unique frames. This is distinctly different from what Borah (2011) found, as she reports 1997-2007 that 32.9\% used consistent (her name for theory-based) frames, and 49.1\% used unique frames (Borah, 2011, p. 255). This shift can be attributed to two things. First, as framing research continues to grow, more and more scholars are using each other's work as a foundation to ground their own research. From the perspective of Entman (1993), this is an encouraging sign. Obviously, if this trend were to continue too far, that would be suboptimal for the future of framing research. It is important that some scholars engage in research that does not presuppose the existence, and effectual power, of frames in order to make sure that research keeps current with any new and developing frames. The other reason this shift may have occurred is that the number of potential journals researched in this study (as opposed to Borah's (2011) work) was wider, suggesting perhaps that with a broader range of study, more framing authors are using each others work than was initially thought.

This does not mean that D'Angelo's (2002) criticism is necessarily ill founded. Consider the results section for Research Question 5 (RQ 5(a): What sorts 
of populations are studied most frequently in framing research? RQ 5(b): Are certain institutions prioritized in framing research above others? RQ 5(c): To what extent does framing research attend to the organizational/political arena? RQ 5(d): To what extent does framing research attend to the public/societal arena? RQ 5(e): To what extent does framing research attend to the news media arena? RQ 5(f): To what extent does framing research attend the counter public arena?). The majority of framing analysis occurs in research regarding news media. This is unsurprising, given the intersection between communication research and media study. However, the heavy focus on frames created from the media, and not created from the public writ large, or counter publics, suggests a failure of the academy to pursue all places that framing takes place.

This is particularly important given the concerns of Carragee and Roefs' (2004) criticism. They attack the lack of framing research that focuses on framing that occurs outside the media (framing that can occur from politicians, organizations, social movements, or other social actors). The research above suggests that that particular part of the criticism is well founded. For the first framing arena, $61.5 \%(\mathrm{~N}=187)$ were from the news media arena, followed by the public / societal arena with $19.1 \%(\mathrm{~N}=58)$, the organizational / political arena reported $15.5 \%(\mathrm{~N}=47)$, and the least being the counter public arena with only $.04 \%$ $(\mathrm{N}=12)$. This speaks to the accuracy of Carragee and Roefs' diagnosis that framing researchers are overly concerned with news media, and not with framing as it occurs in other contexts. 
Carragee and Roefs (2004) desire an examination of the factors that go into media frame construction (frame sponsorship, and other influences on framing content). Our test of Scheufele's (1999) four-phase model demonstrates Carragee and Roefs are well founded in their criticism again. Less than $1 \%$ of articles studied examined the role that individuals played on the framing process itself. This means that even if media are particularly powerful in terms of frame creation, the academy is lacking the research to examine the underlying causes of media framing.

This may be because such a study would prove logistically difficult.

Researchers would have to invest a large amount of resources to truly test an frame creator's attitudes and beliefs, as well as draw causal connections between those beliefs and the framing that occurs in their media content (not to mention the influence on media content by editors, other journalists, etc.). Even if that were true, the ability to test the entirety of the model (tracing a media effect from the creation of the frame, to the distribution, to the effect on the individual in question, to the recreation of said frame in media content) seems a task beyond the scope of any given researcher or institution.

The lack of study on feedback effects also speaks to another problematic part of Scheufele's four-phase model. Each other part - frame building, frame setting, and individual level effects - are defined using applicable research criteria. Frame building examines the creation, or alteration of frames, something that can be tested (particularly if using the frame as the dependent variable). Frame setting examines the ways that frame become part of society more broadly, something easily tested with survey, polling, or other data-measures. Individual level effects can also be 
tested, using frames as an independent variable and testing the changes in attitudes, or beliefs, of individuals exposed to the frames.

However, feedback effects examine how certain members of the public who experience individual level effects of a frame, and also play a role in the creation of frames, link the initial framing effect back into frame building (the creation, or alteration, of frames). This fourth part of the model (feedback effects) is the only part of the model that is defined solely by virtue of the other three parts of the model. This means for this effect to be true, all other parts of the model as explanatory of framing effects must be proven true first. While the creation of the feedback effects portion of the model gives the model great explanatory power, absent a way to test it accurately, it risks becoming unverifiable.

This should be concerning to Scheufele (1999), since it casts serious doubts on the usefulness of his model. The model seems only to work on paper, but not in applied research. Because feedback effects are defined exclusively by their relation to other parts of the model (frame building, individual level effects) instead of by an empirical measurement of some kind (other aspects of the model can easily be operationalized and measured), the model falls apart. In order to capture all areas of framing research, it appears that Scheufele has simply added an "everything else" type of category in order to make the model holistic. While all-inclusive in it's aims, this last category is unquantifiable, and not operationalizable.

This is particularly unfortunate given the large amount of research devoted to frame building. This study indicates $44 \%(\mathrm{~N}=142)$ of the articles coded were concerned with frame building, yet less than $1 \%$ were concerned with feedback 
level effects. This suggests that while plenty of research is looking at the creation of frames, very little of it has examined what roles individuals play within frame construction. This is unsurprising, perhaps, given the popularity of content analysis as a methodology $(53.4 \%, \mathrm{~N}=174)$.

It makes sense that researchers examining content to see if frames occur would treat the frames as the dependent variable, and the particulars of the content as the independent variable. Consider again the example of Fryberg et al. (2012). Researchers examined the role that geography plays in relation to media frames. Researchers employed a content analysis of Arizona based, as well as nationally circulating, newspapers' coverage of a proposed Arizona state immigration law, in order to determine if there was a correlation between geography, and political bias of a given publication, and the way the news media framed the issue of immigration, and value judgments placed on actual immigrants themselves. This sort of content analysis is logistically easy, and allows the scholars to make claims about the sorts of things that impact the creation of news frames, without examining any part of the individuals specifically who did the reporting that ultimately gave way to said frames.

Results for Research Question 3 (RQ3: To what extent does framing research attend to a mixed-frames approach?) were not particularly moving one-way or the other. Given 54.9\% ( $\mathrm{N}=50$ ) did not use a mixed-frames approach, while 45.1 $\%(\mathrm{~N}=41)$ did, of the 91 articles that used experiments that could have employed a mixed-frames approach, research seems somewhat balanced. 
It would be desirable for framing research to have the ability to test effects in a way that does not suffer too greatly from threats to external reliability. Given the arguments made by Sniderman and Theriault (2004) and Borah (2011) that many decisions individuals make are a choice between competing values, or competing frames and, that value conflict is a necessary link between issue framing and political judgment, it seems at first glance that the $54.9 \%$ of articles which did not test a mixed-frames approach would have been improved universally by doing so. Frames are present in a variety of situations and contexts, and as such, in the real world outside the laboratory, it is unlikely for an individual to experience framing effects in such a vacuum.

However, there are two reasons why the results of the current study are encouraging. The first is that the above represents an increase in the study of mixedframes as compared to Borah's findings. Borah only found 3.2\% of studies to have examined mixed frames (2011, p. 257). That is significantly less than $45.1 \%$ found in the current study.

Secondly, it may simply be the case that mixing frames for certain studies is antithetical to the aims of the study. Recall the article by Aday (2010). Aday' examined the effect of visual frames about warfare on individuals' perception of a news story and exposed participants to one of a three conditions: a control, a battle frame, and a casualty frame. In each condition, participants were asked to read a fake newspaper story about the United States' invasion of Iraq. In the control group, individuals only read the text of the story. In the battle frame condition, the same text was accompanied by images of soldiers succeeding in battle, as opposed to the 
casualty frame, where individuals were exposed to the same text paired with images of US soldiers wounded and bleeding on the battlefield. Both before and after exposure to the fake news story, individuals took a short survey on their attitudes, emotions, and support for the United States' invasion of Iraq to examine what effect the visual frames had on the meaning of the newspaper article. It may be that mixing the frames tells the researcher nothing about either frame. Something like a visual frame is complicated because it may be that the end product of mixing two frames is not equivalent to the sum of its parts. It is clear what a casualty frame looks like - it is photographic evidence of the violence of warfare. The "battle frame" Aday uses is more difficult, as showing "victory" in warfare may just be the absence of violence within the imagery. If that is true, then "mixing" exposure to violent imagery, and the lack of violent imagery is impossible, as any mixture may ultimately be considered to still be violent - or still invoke the casualty frame.

In fact, any framing study aimed at showing certain positive or negative frames may not be able to "mix" the frames in a meaningful sense. Researchers that conduct studies about framing information about equivalent choices as either a potential gain, or insurance against a potential loss, serve as good example here. In order to ensure the choice is logically equivalent, the frames in question are perfectly mutually exclusive, and mixing them would be impossible. All this is to say that, by design, researchers may to some degree of frequency be prevented from pursuing a mixed frames approach. We found that about half of the articles that used multiple frames examined a mixed frames approach to their studies, a large increase from Borah's (2011) study which only found 3.2\% of articles to do so. This 
ought to be very encouraging on this front, without concern for the remaining $54.9 \%$ of articles found in this study not to employ a mixed frames approach. The current study offers little assurance as to whether or not framing research is taking adequate methodological care as to mediating and moderating effects. Of the 260 articles that could have reported any mediators or moderators, 93.5\% $(\mathrm{N}=243)$ did not report on them. Only $3.4 \%(\mathrm{~N}=9)$ reported on moderators (exclusively), 2.3\% $(\mathrm{N}=6)$ reported on mediators exclusively, and $0.8 \%(\mathrm{~N}=2)$ reported both mediators and moderators. This is rather small compared to Borah's (2011) findings that $23.8 \%$ of studies reported on moderators, $8.8 \%$ reported on mediators, and 2.2\% reported on both (p. 255). In fact, Borah reports $65.5 \%$ of studies did not report on mediators or moderators, while we found that almost no one $93.5 \%$ reported on such.

There is a serious design flaw that may account for this, however. Researchers in our study were instructed explicitly to code a given article as having reported mediators and moderators, if and only if, a researcher identified explicitly a mediator or moderator in their research. It may have been the case, looking at any given article, that a researcher should have attempted to investigate a potential mediating or moderating relationship. Pragmatically, it would not have been possible to recheck the work of all the authors of every article in this study to ensure there had not been some mediating or moderating effect occurring, and so unless the researcher explicitly used the terms "mediator" or "moderator" to explain a relationship, our coders did not code that such effect was examined. 
However, more accurately, it would be irresponsible to interpret the findings of this study to say that framing researchers are not examining mediating or moderating effects $93.5 \%$ of the time. Given the need for brevity in reporting and publishing data, it may very well be the case that researchers did test mediators and moderators, and, as a result of not finding significant effects to either, not reported any mediators or moderators. Unfortunately, from the standpoint of this study, the frequency at which framing researchers are engaged in looking for mediating or moderating effects is unknown - only the frequency at which those effects are reported are known.

In summary, framing research is primarily concerned with frames originating from news media (for the first framing arena, of the 304 articles, $61.5 \%$ $(\mathrm{N}=187)$ were from the news media arena). While perhaps unsurprising, it remains unsettling that so little research seems interested in marginalized and minority populations. Due to the unique circumstances of these communities, research questions aimed towards society at large do not always adequately address circumstances unique to counterpublics. Given the relatively large attention paid to the public at large in the above analysis, it seems as if framing research desires to paint with a broad brush.

Less than one percent of research examined anything in the counterpublic arena. Of those articles that did, they addressed exclusively men who have sex with men as a unique population (with specific communication, and healthcommunication concerns). This seems woefully inadequate on two fronts: first, that this small number or articles represents a substantive and robust vein of research 
concerning this group (men who have sex with men), but second, that men who have sex with men would be the only group research ought to pay attention to.

It was expected that more communication researchers would be concerned with the way different groups create meaning, and as such, would be examined in the context of framing research. It is surprising that more of the research did not address concerns of women, of non-white racial identities, or of the experiences of immigrants and immigrant's families. Given the saliency of these groups as represented in contemporary politics, it seems strange to find research concerning these populations to be lacking. It does not seem that there are substantial logistical barriers to studying these populations.

Perhaps part of the lack of focus on counterpublics can be explained with the high level of content analyses employed by most framing researchers (after all, it is easier to simply use texts that are widely circulated and easily available, such as newspapers, which also do not pay special attention to marginalized populations). This demonstrates a large hole in the way framing scholars approach research. Without working a counterpublic lens into research design, research functions to exclude these populations by simply examining either media, or the public, as a whole. This speaks exactly to Warner's (2002) criticism; that academic work concerned exclusively with the public writ large will exclude, and be ignorant to, concerns of many parts of the population. Warner's initial criticism of Habermas was to demonstrate that there is no effective technique to engage all the public at once, as most "one size fits all" approaches leave out those who have been historically excluded from the public. This study shows Warner's concern as 
germane to framing research. This is concerning, because it sheds doubt on the claims made by most framing effect scholars. If researchers are making arguments, that framing effects result in a change of public opinion, attitudes, beliefs, reactions, etc., but are not taking into account the way that different groups within that public create unique sets of meanings, attitudes, beliefs, reactions, and so forth, then no framing effect study is doing its due diligence in explaining framing effects.

Research that exclusively focuses on the majority may miss many significant issues facing members of "counterpublics". Warner (2002) and others argue that it is important for researchers to use their position to examine historically disenfranchised groups. To devote so many resources to the study of media frames, and omit the framing done by other groups seems a missed opportunity. Meaning creation occurs in a variety of contexts, and understanding the ways in which certain groups organize and emphasize their perceived reality may prove valuable towards research accuracy and efficacy. Future research would do well to attend to these concerns. 


\section{Limitations}

Lastly, this study was hampered by a few major limitations. While some have been identified above, the greatest limitation, bar none, was the range of articles collected for study. Searching exclusively with the terms "framing" and "frames" returned far too many articles that did not contribute to framing research. Only $22.5 \%$ of articles that returned were useful for the purposes of this study. Borah's (2011) work reported on a census of a total of 379 articles from 93 journals (p. 254). The scope of this project was much bigger, given we ultimately searched 2942 journals, and retrieved 7965 unique articles.

This caused a few problems. First, it meant that unlike Borah (2011) who could code every article in her census, we could only manage a sample of the total articles for coding. Secondly, wading through so many useless articles cost all five coders valuable time. Having to read through nearly 19 useless articles just to find one worth coding takes a toll on any researcher. Additionally, such a low success rate of relevant articles probably speaks to a clumsy research design that was inefficient.

Also, as mentioned above in the inter-coder reliability section, the authors of the coding manual and codebook severely underestimated the confusion coding for multiple frames would cause. Given high agreement on the first frame studied in a given article, and the large disagreement in number of frames studied, and chronological order of frames studied, the research project designers should have used a different system to code for multiple frames studied. Perhaps a simpler 
design, only coding the first frame studied in every given article, and a single "more than one frame" code option would have improved reliability greatly, and given more room to make more nuanced claims about the data.

Additionally, inter-coder agreement quickly decreases as coders evaluated a second, or third frame in the study. This is likely due to disagreement over what constitutes as primary, secondary, or tertiary frame. Also, giving three opportunities to code frames, followed by a "more than three frames" code was arbitrary; there is no reason the coders were not given four opportunities, or forty opportunities, to code frames. The end result of three opportunities meant that coders did not always code every frame in a given article, and also caused great disagreement. More time should have been spent to develop a system as to what constitutes a second, third, or even fourth frame.

The study also would have been improved if the category of " $0=$ No Second Frame" was the a separate option, distinct from the coding opportunity that coders used to note if the second frame was from a certain arena (organizational/political, public/societal, news media, counterpublic), certain level (cognitive, discourse, textual), and certain variable (independent or dependent). It was impossible to test how often articles studied more than one frame with any substantive reliability, since if a coder thought the article had a second or third frame, there was disagreement on how that frame ought have been coded. Perhaps with the chance for a coder to mark "yes/no" on the existence of a second, or third, frame as it's own category would give us the statistical tools necessary to code how often studies examined more than one frame with greater confidence. 
Lastly, it is unclear that the study was able to explicitly shed light on the broader thematic issues underlying the research questions. The hope is that this study goes some way to establishing what a dominant paradigm in framing would be, and how framing research could be measured to examine such a paradigm. That may be impossible. Borah (2011) concludes her study arguing, "framing is indeed still a fractured paradigm. But the double life of frames and its roots in various disciplines makes it impossible to be otherwise" (p. 257). This seems to be the most charitable conclusion from our study as well. Framing researchers ask a broad range of questions, on a broad range of subjects, at a broad range of levels. What is to be taken from that? Perhaps the conclusion ought be that D'Angelo (2002) is correct that this multi-paradigmatic approach to research is ultimately a good thing. However, the lack of attention paid to counter publics, feedback effects, mediators, and moderators, all speak to evidence that scholars may not be conducting framing research in the most optimal way. Ultimately, this study demonstrates several areas of improvement in framing research (mixed frames study, frame building studies) consistent with Borah's (2011) calls for improvement. While it may not be possible to conclusively answer the disagreement between Entman (1993) and D'Angelo (2002), framing research seems to be getting closer to an answer in recent years, than from 1997-2007. 


\section{References}

Aday, Sean. "Leading the Charge: Media, Elites, and the Use of Emotion in Stimulating Rally Effects in Wartime." Journal of Communication 60, no. 3 (September 2010): 440-65. doi:10.1111/j.1460-2466.2010.01489.x.

Barry, Colleen L., Victoria L. Brescoll, and Sarah E. Gollust. “Framing Childhood Obesity: How Individualizing the Problem Affects Public Support for Prevention." Political Psychology 34, no. 3 (June 1, 2013): 327-49. doi:10.1111/pops.12018.

Borah, Porismita (2011). “Conceptual Issues in Framing Theory: A Systematic Examination of a Decade’s Literature." Journal of Communication 61, no. 2 (April 2011): 246-63. doi:10.1111/j.1460-2466.2011.01539.x.

Carragee, K., \& Roefs, W. (2004). The neglect of power in recent framing research. Journal of Communication, 54(2), 214-233.

Corcoran, Paul E. "Presidential Concession Speeches: The Rhetoric of Defeat."

Political Communication 11, no. 2 (April 1994): 109-31.

D’Angelo, Paul. “News Framing as a Multiparadigmatic Research Program: A Response to Entman." Journal of Communication 52, no. 4 (December 2002): 870.

Druckman, J. (2001). The implications of framing effects for citizen competence. Political

Behavior, 23(3), 225-256. 
Entman, Robert M. "Framing: Toward Clarification of a Fractured Paradigm." Journal of Communication 43, no. 4 (1993): 51-58.

Fryberg, Stephanie A., Nicole M. Stephens, Rebecca Covarrubias, Hazel Rose Markus, Erin D. Carter, Giselle A. Laiduc, and Ana J. Salido. "How the Media Frames the Immigration Debate: The Critical Role of Location and Politics." Analyses of Social Issues and Public Policy 12, no. 1 (December 1, 2012): 96-112. doi:10.1111/j.1530-2415.2011.01259.x.

Gitlin, T. (1980). The whole world is watching: Mass media in the making \& unmaking of the new left. Berkeley: University of California Press.

Goffman, E. (1974). Frame analysis: An essay on the organization of experience. Cambridge, MA: Harvard University Press.

Herbst, Susan. “Walter Lippmannn's Public Opinion, Revisited.” The Harvard International Journal of Press/Politics 4, no. 2 (March 1, 1999): 88-93. doi:10.1177/1081180X99004002009.

Ho, S. Iimay, and Megan E. Rolfe. "Same-Sex Partner Immigration and the Civil Rights Frame: A Comparative Study of Australia, Israel, and the USA." International Journal of Comparative Sociology 52, no. 5 (October 1, 2011): 390-412. doi:10.1177/0020715211425426.

Igartua, Juan-Jos, and Lifen Cheng. “Moderating Effect of Group Cue While Processing News on Immigration: Is the Framing Effect a Heuristic Process?" Journal of Communication 59, no. 4 (December 2009): 726-49. doi:10.1111/j.1460-2466.2009.01454.x. 
Jasperson, Amy E., Dhavan V. Shah, Mark Watts, Ronald J. Faber, and David P. Fan.

"Framing and the Public Agenda: Media Effects on the Importance of the Federal Budget Deficit." Political Communication 15, no. 2 (April 1998): 205-24. doi:10.1080/105846098199037.

Joslyn, Mark R., and Donald P. Haider-Markel. "Framing Effects on Personal Opinion and Perception of Public Opinion: The Cases of Physician-Assisted Suicide and Social Security." Social Science Quarterly 83, no. 3 (September 1, 2002): 690706. doi:10.1111/1540-6237.00109.

Kuhn, Thomas S. The Structure of Scientific Revolutions. 2nd ed., enl.. Chicago: University of Chicago Press, 1970.

Kaid, Lynda Lee, Ralph Negrine, and Kirk Hallahan. "Classic Books Revisited.” Journalism Studies 5, no. 3 (August 2004): 409-15. doi:10.1080/1461670042000246142.

Lippmannn. Walter. Public Opinion. 1st Free Press pbks. ed.. New York: Free Press Paperbacks, 1997.

Miller, P. M., \& Fagley, N. S. (1991). The effects of framing, problem variations, and providing rationale on choice. Personality and Social Psychology Bulletin, 17(5), 517-522

Scheufele, D.A. "Framing as a Theory of Media Effects." Journal of Communication 49, no. 1 (1999): 103-22. 
Scheufele, D. A., \& Tewksbury, D. (2007). Framing, agenda setting, and priming: The evolution of three media effects models. Journal of Communication, 57(1), 920.5

Tversky, Amos, and Daniel Kahneman. "The Framing of Decisions and the Psychology of Choice." Science, New Series, 211, no. 4481 (January 30, 1981): 453-58.

Tewksbury, David, Jennifer Jones, Matthew W. Peske, Ashlea Raymond, and William Vig. "The Interaction of News and Advocate Frames: Manipulating Audience Perceptions of a Local Public Policy Issue." Journalism \& Mass Communication Quarterly 77, no. 4 (Winter 2000): 804-29.

Warner, Michael. "Publics and Counterpublics." Public Culture 14, no. 1 (2002): 4990. 